\title{
Oboe Transparency Results - Oboes 1-9
}

\author{
R.A. Heinle
}

October 15, 2002

U.S. Department of Energy

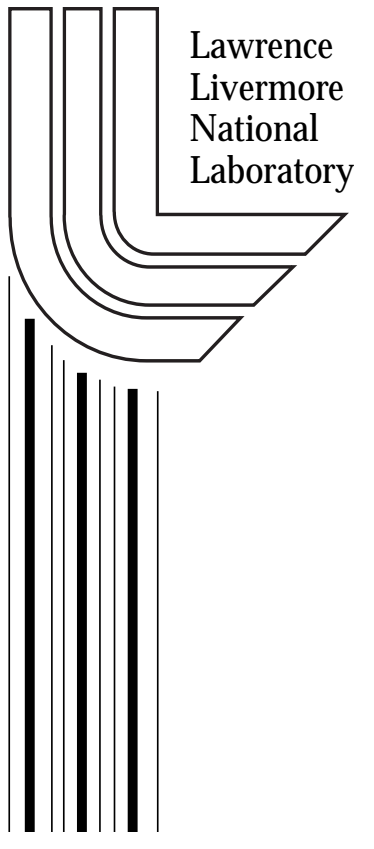




\section{DISCLAIMER}

This document was prepared as an account of work sponsored by an agency of the United States Government. Neither the United States Government nor the University of California nor any of their employees, makes any warranty, express or implied, or assumes any legal liability or responsibility for the accuracy, completeness, or usefulness of any information, apparatus, product, or process disclosed, or represents that its use would not infringe privately owned rights. Reference herein to any specific commercial product, process, or service by trade name, trademark, manufacturer, or otherwise, does not necessarily constitute or imply its endorsement, recommendation, or favoring by the United States Government or the University of California. The views and opinions of authors expressed herein do not necessarily state or reflect those of the United States Government or the University of California, and shall not be used for advertising or product endorsement purposes.

This work was performed under the auspices of the U. S. Department of Energy by the University of California, Lawrence Livermore National Laboratory under Contract No. W-7405-Eng-48.

This report has been reproduced directly from the best available copy.

Available electronically at http://www.doe.gov/bridge

Available for a processing fee to U.S. Department of Energy and its contractors in paper from

U.S. Department of Energy

Office of Scientific and Technical Information

P.O. Box 62

Oak Ridge, TN 37831-0062

Telephone: (865) 576-8401

Facsimile: (865) 576-5728

E-mail: reports@adonis.osti.gov

Available for the sale to the public from

U.S. Department of Commerce

National Technical Information Service 5285 Port Royal Road

Springfield, VA 22161

Telephone: (800) 553-6847

Facsimile: (703) 605-6900

E-mail: orders@ntis.fedworld.gov

Online ordering: http://www.ntis.gov/ordering.htm

OR

Lawrence Livermore National Laboratory

Technical Information Department's Digital Library

http://www.llnl.gov/tid/Library.html 


\title{
OBOE TRANSPARENCY RESULTS - OBOES 1-9
}

\author{
by
}

\author{
R. A. Heinle
}

October 15, 2002

\section{Introduction and Motivation}

The motivation for the "Transparency" experiment is that DOE/DP would like to have data available to show to interested parties, such as the JASONs. The U1a subcritical experiments are consistent with U.S. policy on nuclear testing. This would be done in a spirit of "Transparency" if doubts should arise. Thus, the objective of the "Transparency" measurements on the Oboe series is to place an upper bound on the nuclear energy released in the subcritical experiments.

Two separate experimental packages cover the transparency measurement issue thoroughly. These are:

1. Neutron Track-Etch Dosimetry.

2. Scintillator Fission Neutron/Gamma Rate Measurement.

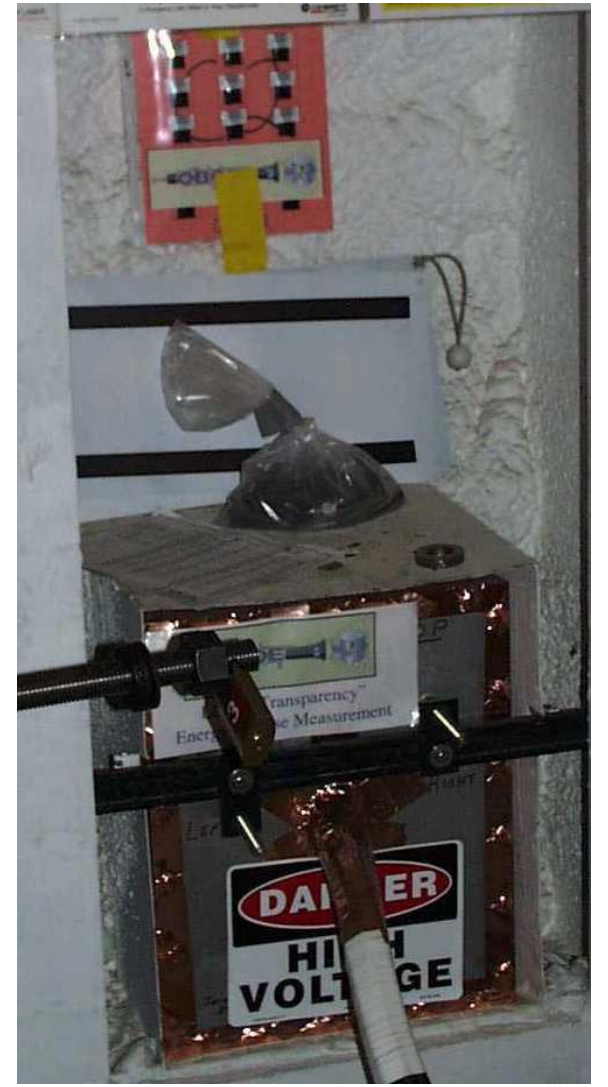

Fig. 1. Transparency detectors on Oboe Barrier.
Because the containment barrier is only 1-inch steel, plus 6-inch shotcrete, it is quite transparent to fission neutrons and, thus, both experiments can be mounted outside the containment barrier and can be recovered post shot. An additional group of dosimeters was placed on the lid of the vessel for greater sensitivity.

We describe briefly the results of both of the experiments below. Fig. 1 shows a photo of the containment barrier and one of the dosimeter arrays and the Scintillator measurement. Fig. 2 shows each experiment location on the containment barrier. Fig. 3 shows a photo of a dosimeter array placed on the lid of the vessel. For a complete description of each experiment, please see the Oboe Subcritical Experiment Pre-Operational Report (UCRL-ID-135569).

\section{Sensitivity Calculations}

To determine the in situ sensitivity of the track etch dosimeters and the Scintillator Fission Neutron/Gamma Rate Measurement, a Monte-Carlo simulation of the problem was set up and run with the COG code. ${ }^{\text {i }}$ 

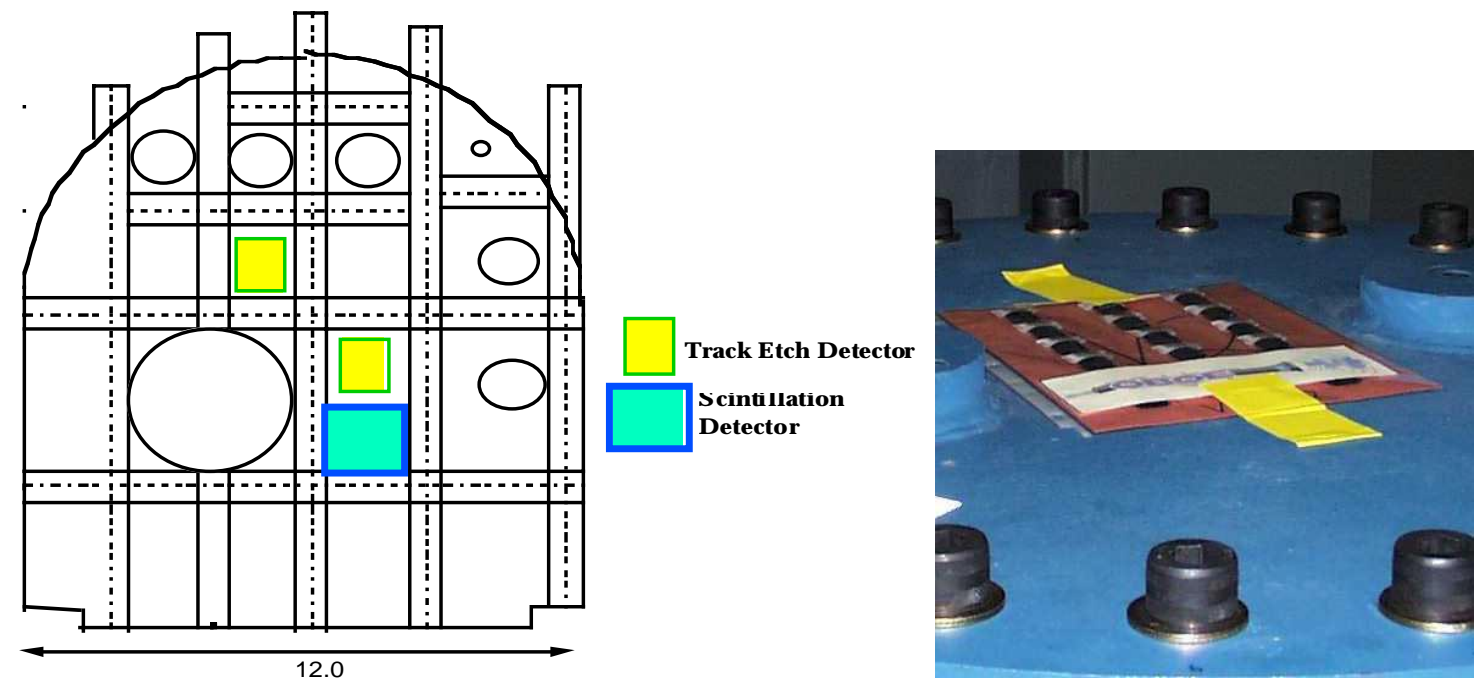

Fig. 2. The Oboe Barrier.

Fig. 3. Dosimeters on vessel lid.

A simulated device source was placed in the extreme rear of the zero room that we modeled, about $16 \mathrm{~m}$ away from the barrier. The probability of neutrons and photons, from the source crossing the barrier, were computed. The appropriate detector response functions ${ }^{\text {ii }}$ were included for the active PM detectors and the dosimeters. A summary of those calculations is shown below in Table 1.

Table 1. Transparency Calculations.

Fissions/1 gram energy release

$n$ source for 1 gram energy release at outer sfc of $\mathrm{HE}$

$\gamma$ Source for 1 gram energy release at outer sfc of $\mathrm{HE}$

Barrier Transmission

Detector Response

Detector Area

Solid angle (based on $1582 \mathrm{~cm}$ distance)

\section{Active Detector}

Neutron Flux into detector/g TNT energy release

Gamma Flux into detector/g TNT energy release

Track Etch Dosimeters

Barrier Expected track value for 1 gram "device"

Lid Expected track value for 1 gram "device"

\begin{tabular}{|c|c|}
\hline Neutrons & $\gamma-M e V$ \\
\hline \multicolumn{2}{|c|}{$1.40 E+14$ fissions } \\
\hline \multicolumn{2}{|l|}{$3.04 E+14$} \\
\hline & $7.25 E+13$ \\
\hline $1.64 \mathrm{E}-01$ & $4.49 \mathrm{E}-01$ \\
\hline 6.64E-02 & $7.28 \mathrm{E}-01$ \\
\hline \multicolumn{2}{|c|}{$232 \mathrm{~cm}^{2}$} \\
\hline $37676 E-06$ & \\
\hline
\end{tabular}

$3.68 \mathrm{E}+08$ neutrons

$2.40 \mathrm{E}+08 \gamma-\mathrm{MeV}$

$140.53 \mathrm{tracks} /\left(\mathrm{cm}^{2}\right.$-gram TNT $)$
$2.44 \mathrm{E}+05 \mathrm{tracks} /\left(\mathrm{cm}^{2}\right.$-gram TNT $)$

\section{Neutron Track-Etch Dosimeter}

The neutron track-etch dosimeter measurements are simple and electronics free. These involve standard integrated neutron dosimetry using CR-39 track-etch detectors 
outside the containment barrier and on the vessel lid. For each SCE, four 8-1/2 x 11" cards, each containing 16 dosimeters, are placed on the left rib of the $102 \mathrm{drift}$, on the center of the containment barrier, on the left side of the barrier, and on the lid of the vessel. The dosimeters are placed before firing and recovered when the zero room is re-entered.

Upon recovery, the sample cards are retrieved, the dosimeters are removed from the cards and placed in bags. These bags are delivered to Bechtel Nevada Dosimetry, who processes the data and returns the results to LLNL several weeks later. These dosimeters are processed "blind." BN does not know which dosimeter was at what location. BN then emails LLNL the results back in the form of spreadsheets. We sort the results by actual location and analyze the data using a calibration value obtained by averaging all of the BN calibrations for each run on each SCE in the series.

The number of tracks/foil and the variance is computed by simple averaging from the sorted $\mathrm{BN}$ data. Then, the value for $\mathrm{L}_{\mathrm{C}}$, the decision level, is computed for the $99.9 \%$ confidence level on a per foil basis.

Here we used the fact that $\mathrm{L}_{\mathrm{C}}=\mathrm{t}_{.001} \sqrt{ }(2 . * \mathrm{~B})$ where $\mathrm{t}_{.001}$ is the "student's $\mathrm{t}$ " distribution for the $99.9 \%$ confidence level, based on a large sample size, with B being the variance. ${ }^{\mathrm{iii}}$ The values computed for $\mathrm{L}_{\mathrm{C}}$ in counts/foil are then extended to each array of 16 foils by dividing the appropriate sensitivity values and $\sqrt{ } 16$ to apply the fact that we have 16 dosimeters on each card station (Currie). Similarly, we add in quadrature the results from the two cards of dosimeters that were on the containment barrier for the event. A summary of the "Transparency" dosimeter results from each SCE is included at the end of this section in Tables 2-10.

Oboe 9 was treated somewhat differently. Bechtel Nevada stopped analyzing the dosimeter data themselves and contracted with an outside organization (ICN Corporation) to provide the dosimeters and the post-collection analysis. ICN was unable to provide track density, but rather supplied dose in mrem per dosimeter directly. Aside from this, the dosimeters were treated the same statistically.

Table 11 summarizes the dosimeter results from each of the segments in the Oboe series. To help understand Table 11, we look at Oboe 1. On Oboe 1, for the 32 foils on the Oboe Containment Barrier, we get an average of 4.8 tracks/foil, compared to an average background of 5.6 tracks/foil. We are $99.9 \%$ certain that we had no energy release above 0.08 grams TNT; such a release would have required an average track value greater than 8.97 tracks.

For the 16 foils on the Oboe 1 Vessel, we get an average of 5.9 tracks/foil compared to an average background of 5.6 tracks / foil. We are $99.9 \%$ certain that we had no energy release above $0.08 \mathrm{mg}$ TNT; such a release would have required an average track value greater than 9.89 tracks. 
Table 2. Oboe 1 Summary. |OBOE 1 SUMMARY

Pre Event Average/foil
Variance
$99.9 \%$ DL/foil
Level threshold for 16 foils
For all 32 foils on the Oboe 1 Containment barrier we
Event Average/foil
Variance on 32 foils
$99.9 \%$ DL/foil
Level threshold for 16 foils
Variance on 32 foils
$99.9 \%$ DL/foil
Level threshold for 32 foils
Average background counts
Table 3 . Oboe $2 \mathrm{Summary}$.
OBO
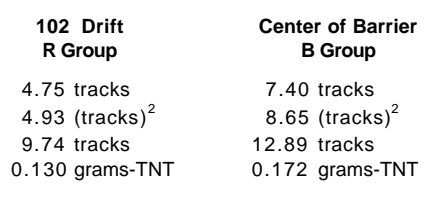
5.24 tracks
4.96 (tracks) $^{2}$
9.76 tracks

0.131 grams-TNT
4.759 tracks
3.752 (tracks) $^{2}$
8.49 tracks
0.114 grams-TNT

4.20 tracks

4.20 tracks
8.97 tracks $^{2}$

0.085 grams-TNT

5.587 tracks

$\begin{array}{cc}\begin{array}{c}\text { Right side of barrier } \\ \text { C Group }\end{array} & \begin{array}{c}\text { Vessel } \\ \text { V Group }\end{array} \\ 5.13 \text { tracks } & 5.417 \text { tracks } \\ 4.38 \text { (tracks) } & 4.85 \text { (tracks) } \\ 9.18 \text { tracks } & 9.65 \text { tracks } \\ 0.123 \text { grams-TNT } & 0.001 \text { grams-TNT }\end{array}$

4.787 tracks

4.65 (tracks) $^{2}$

9.45 tracks

0.126 grams-TNT

5.934 tracks

$5.091{\text { (tracks })^{2}}^{2}$

9.89 tracks

0.001 grams-TNT

\section{Event Average/foil \\ Variance \\ $99.9 \% \mathrm{DL} /$ foil}

Level threshold for 16 foils

For all 32 foils on the Oboe Containment barrier we get:

Event Average on 32 foils

Variance on 32 foils

$99.9 \% \mathrm{DL} /$ foil

Level threshold for $\mathbf{3 2}$ foils

Average background counts

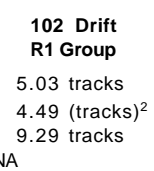

NA

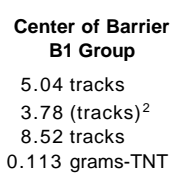

4.88 tracks

4.23 tracks $^{2}$

9.01 tracks

0.084 grams-TNT equivalent energy release

5.030 tracks
Right side of barrier
C1 Group
4.71 tracks
4.67 (tracks) $^{2}$
9.48 tracks
0.125 grams-TNT

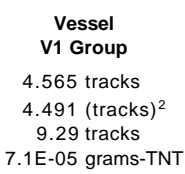

Table 4. Oboe 3 Summary. OBOE 3 SUMMARY

\section{Event Average/foil \\ Variance \\ $99.9 \% \mathrm{DL} /$ foil}

Level threshold for 16 foils

For all 32 foils on the Oboe Containment barrier we get:

Event Average on 32 foils

Variance on 32 foils

$99.9 \% \mathrm{DL} / \mathrm{foil}$

Level threshold for $\mathbf{3 2}$ foils

Average background counts

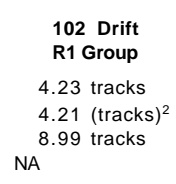
Center of Barrier
B1 Group
4.95 tracks
4.41 (tracks) ${ }^{2}$
9.20 tracks
9.20 tracks
0.132 grams-TNT
Right side of barrier
C1 Group
4.17 tracks
4.63 (tracks) $^{2}$
9.44 tracks
0.135 grams-TNT

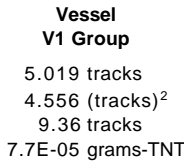

4.56 tracks

4.52 tracks $^{2}$

9.32 tracks

0.094 grams-TNT equivalent energy release

4.231 tracks 
Table 5. Oboe 4 Summary. OBOE 4 SUMMARY

Event Average/foil

Variance

$99.9 \% \mathrm{DL} /$ foil

Level threshold for 16 foils

For all 32 foils on the Oboe Containment barrier we get:

Event Average on 32 foils

Variance on $\mathbf{3 2}$ foils

$99.9 \% \mathrm{DL} /$ foil

Level threshold for 32 foils

Average background counts

Table 6. Oboe 5 Summary. OBOE 5 SUMMARY

\section{Event Average/foil \\ Variance \\ $99.9 \% \mathrm{DL} / \mathrm{foi}$}

Level threshold for 16 foils

For all 32 foils on the Oboe Containment barrier we get:

Event Average on 32 foils

Variance on $\mathbf{3 2}$ foils

$99.9 \% \mathrm{DL} /$ foil

Level threshold for $\mathbf{3 2}$ foils

Average background counts

\section{Table 7. Oboe 6 Summary.}

\section{OBOE 6 SUMMARY}

\section{Event Average/foil}

Variance

$99.9 \%$ DL/foil

Level threshold for 16 foils

102 Drift
R1 Group
2.58 tracks
2.58 (tracks)
7.04 tracks
NA

$\begin{gathered}\text { Center of Barrier } \\ \text { B1 Group }\end{gathered}$
2.95 tracks
3.12 (tracks) $^{2}$
7.75 tracks
0.148 grams-TNT

$$
\begin{gathered}
\text { Right side of barrier } \\
\text { C1 Group } \\
2.85 \text { tracks } \\
3.13 \text { (tracks) } \\
7.76 \text { tracks } \\
0.149 \text { grams-TNT }
\end{gathered}
$$

2.90 tracks

3.13 tracks $^{2}$

7.75 tracks

0.105 grams-TNT equivalent energy release

2.583 tracks

$\begin{gathered}\text { Center of Barrier } \\ \text { B1 Group }\end{gathered}$
3.55 tracks
2.83 (tracks) $^{2}$
7.37 tracks
0.164 grams-TNT
Right side of barrier C1 Group
3.56 tracks
3.75 (tracks)
8.49 tracks
0.188 grams-TNT

8.78 tracks

0.164 grams-TN
3.55 tracks

3.29 tracks $^{2}$

7.95 tracks

0.125 grams-TNT equivalent energy release

3.491 tracks

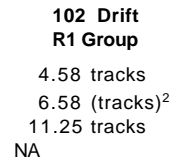

NA

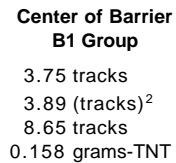

0.158 grams-TNT

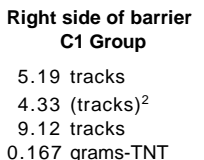

0.167 grams-TNT

$$
\begin{gathered}
\text { Vessel } \\
\text { V1 Group } \\
3.231 \text { tracks } \\
3.031 \text { (tracks) }^{2} \\
7.63 \text { tracks } \\
.4 \mathrm{E}-05 \text { grams-TNT }
\end{gathered}
$$

\begin{tabular}{|c|c|c|}
\hline & R1 Group & B1 Group \\
\hline Event Average/foil & 3.56 tracks & 3.71 tracks \\
\hline Variance & $4.04(\text { tracks })^{2}$ & 3.41 (tracks) $^{2}$ \\
\hline $99.9 \% \mathrm{DL} /$ foil & 8.81 tracks & 8.09 tracks \\
\hline Level threshold for 16 foils & NA & 0.189 grams-TNT \\
\hline \multicolumn{3}{|c|}{ For all 32 foils on the Oboe Containment barrier we get: } \\
\hline Event Average on 32 foils & \multicolumn{2}{|l|}{3.71 tracks } \\
\hline $\begin{array}{l}\text { Variance on } 32 \text { foils } \\
99.9 \% \text { DL/foil } \\
\text { Level threshold for } 32 \text { foils }\end{array}$ & $\begin{array}{l}3.50 \text { tracks }^{2} \\
8.20 \text { tracks } \\
0.136 \text { grams-TN }\end{array}$ & lent energy release \\
\hline Average background counts & \multicolumn{2}{|l|}{3.565 tracks } \\
\hline
\end{tabular}

For all 32 foils on the Oboe Containment barrier we get:

Event Average on 32 foils

Variance on 32 foils

$99.9 \% \mathrm{DL} / \mathrm{foil}$

Level threshold for 32 foils

Average background counts

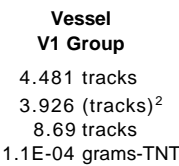

1.1E-04 grams-TNT

\section{Table 8. Oboe 7 Summary. OBOE 7 SUMMARY}

4.47 tracks

4.11 tracks $^{2}$

8.89 tracks

0.115 grams-TNT equivalent energy release

4.583 tracks

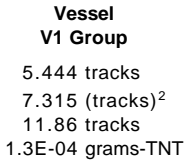

1.3E-04 grams-TNT 
Table 9. Oboe 8 Summary. OBOE 8 SUMMARY

\begin{tabular}{|c|c|c|}
\hline & $\begin{array}{l}102 \text { Drift } \\
\text { R1 Group }\end{array}$ & $\begin{array}{c}\text { Center of Barrier } \\
\text { B1 Group }\end{array}$ \\
\hline Event Average/foil & 5.20 tracks & 5.54 tracks \\
\hline $\begin{array}{l}\text { Variance } \\
99.9 \% \mathrm{DL} / \text { foil }\end{array}$ & $\begin{array}{l}4.62 \text { (tracks) }^{2} \\
9.43 \text { tracks }\end{array}$ & $\begin{array}{l}4.40 \text { (tracks) }^{2} \\
9.19 \text { tracks }\end{array}$ \\
\hline Level threshold for 16 foils & NA & 0.240 grams-TNT \\
\hline \multicolumn{3}{|c|}{ For all 32 foils on the Oboe Containment barrier we get: } \\
\hline Event Average on 32 foils & \multicolumn{2}{|l|}{5.15 tracks } \\
\hline $\begin{array}{l}\text { Variance on } 32 \text { foils } \\
99.9 \% \text { DL/foil } \\
\text { Level threshold for } 32 \text { foils }\end{array}$ & \multicolumn{2}{|l|}{$\begin{array}{l}5.55 \text { tracks }^{2} \\
10.32 \text { tracks } \\
0.191 \text { grams-TN }\end{array}$} \\
\hline Average background counts & \multicolumn{2}{|l|}{5.204 tracks } \\
\hline
\end{tabular}

Table 10. Oboe 9 Summary. OBOE 9 SUMMARY

\begin{tabular}{|c|c|c|c|c|}
\hline & $\begin{array}{l}102 \text { Drift } \\
\text { R1 Group }\end{array}$ & $\begin{array}{l}\text { Center of Barrier } \\
\text { B1 Group }\end{array}$ & $\begin{array}{l}\text { Right side of barrier } \\
\text { C1 Group }\end{array}$ & $\begin{array}{l}\text { Vessel } \\
\text { V1 Group }\end{array}$ \\
\hline Event Average/foil & $1.61 \mathrm{mrem}$ & $3.59 \mathrm{mrem}$ & $3.67 \mathrm{mrem}$ & $3.000 \mathrm{mrem}$ \\
\hline $\begin{array}{l}\text { Variance } \\
99.9 \% \mathrm{DL} / \text { foil }\end{array}$ & $\begin{array}{l}10.84(\mathrm{mrem})^{2} \\
14.43 \mathrm{mrem}\end{array}$ & $\begin{array}{l}15.13(\mathrm{mrem})^{2} \\
17.05 \mathrm{mrem}\end{array}$ & $\begin{array}{l}11.41(\mathrm{mrem})^{2} \\
14.81 \mathrm{mrem}\end{array}$ & $\begin{array}{l}16.588(\mathrm{mrem})^{2} \\
17.86 \mathrm{mrem}\end{array}$ \\
\hline Level threshold for 16 foils & NA & 0.110 grams-TNT & 0.095 grams-TNT & 0.0001 grams-TNT \\
\hline
\end{tabular}

For all 32 foils on the Oboe Containment barrier we get:

Event Average on 32 foils

Variance on 32 foils

$99.9 \% \mathrm{DL} /$ foil

Level threshold for 32 foils

$3.63 \mathrm{mrem}$

$13.27(\mathrm{mrem})^{2}$

$15.97 \mathrm{mrem}$

0.073 grams-TNT equivalent energy release

Average background dose

$1.611 \mathrm{mrem}$

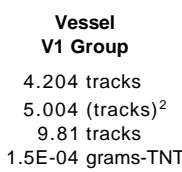

11.34 tra

1.34 tracks
0.296 grams-TN

\section{Table 11. Oboe Dosimeter Summary.}

\begin{tabular}{|c|c|c|c|c|c|c|c|c|c|}
\hline Background counts & $\begin{array}{r}\text { Oboe } 1 \\
5.59\end{array}$ & $\begin{array}{r}\text { Oboe } 2 \\
5.03\end{array}$ & $\begin{array}{r}\text { Oboe } 3 \\
4.23\end{array}$ & $\begin{array}{r}\text { Oboe } 4 \\
2.58\end{array}$ & $\begin{array}{r}\text { Oboe } 5 \\
3.49\end{array}$ & $\begin{array}{r}\text { Oboe } 6 \\
4.58\end{array}$ & $\begin{array}{r}\text { Oboe } 7 \\
3.56\end{array}$ & $\begin{array}{r}\text { Oboe } 8 \\
5.20\end{array}$ & $\begin{array}{r}\text { Oboe } \mathbf{9}^{*} \\
1.61\end{array}$ \\
\hline $\begin{array}{l}\text { Barrier counts } \\
99.9 \% \text { Decision Level }\end{array}$ & $\begin{array}{l}4.80 \\
8.97\end{array}$ & $\begin{array}{l}4.88 \\
9.01\end{array}$ & $\begin{array}{l}4.56 \\
9.32\end{array}$ & $\begin{array}{l}2.90 \\
7.75\end{array}$ & $\begin{array}{l}3.55 \\
7.95\end{array}$ & $\begin{array}{l}4.47 \\
8.89\end{array}$ & $\begin{array}{l}3.71 \\
8.20\end{array}$ & $\begin{array}{r}5.15 \\
10.32\end{array}$ & $\begin{array}{r}3.63 \\
15.97\end{array}$ \\
\hline Max Energy release based on DL (mg TNT eq.) & 85.00 & 84.00 & 94.00 & 105.00 & 125.00 & 115.00 & 136.00 & 191.00 & $\begin{array}{r}73.00 \\
3.00\end{array}$ \\
\hline $\begin{array}{l}\text { Lid counts } \\
99.9 \% \text { Decision Level }\end{array}$ & $\begin{array}{l}5.93 \\
9.89\end{array}$ & $\begin{array}{l}4.57 \\
9.29\end{array}$ & $\begin{array}{l}5.02 \\
9.36\end{array}$ & $\begin{array}{l}3.23 \\
7.63\end{array}$ & $\begin{array}{l}4.48 \\
8.69\end{array}$ & $\begin{array}{r}5.44 \\
11.86\end{array}$ & $\begin{array}{l}3.57 \\
7.68\end{array}$ & $\begin{array}{l}4.20 \\
9.87\end{array}$ & $\begin{array}{r}3.00 \\
17.86\end{array}$ \\
\hline Max Energy release based on DL (mg TNT eq.) & 0.08 & 0.07 & 0.08 & 0.08 & 0.11 & 0.13 & 0.10 & 0.15 & 0.10 \\
\hline
\end{tabular}

* On Oboe 9 the units are mrem rather than counts. The effective area read on each dosimeter on Oboe 9 was $1.6 \mathrm{~cm}^{2}$

rather than $.09 \mathrm{~cm}^{2}$ as the rest of Oboes $1-8$.

\section{Scintillator Fission Neutron/Gamma Rate Measurement}

To detect neutrons and gammas associated with fission energy release using active methods, we used a Bechtel-Nevada MHD 24-multihead, plastic scintillator detector unit identical to those that were fielded on earlier nuclear safety shots. Indeed, the unit we use for Oboe has been previously used on other SCEs and was assembled for GABBS-Lime, a canceled nuclear test.

The Oboe MHD-24 is a 6.0-inch cube of BC-404 plastic scintillator, viewed by three photomultipliers (BN Type PMH-5) and a photodiode (BN Type PDH-4) mounted on four faces of the cube. The detector was mounted in an EMI shielded aluminum box and placed in a space in the I-beam lattice of the outer containment barrier, just below and to the right of the crawl tube as shown in Fig. 2. Jumper cables to the detector heads are made with double-shielded, RF-214 cable, with identical cable, EMI shielding practice, as on previous safety shots. 
In order to verify that all diagnostic equipment, including the detector itself, is active and working at event time, several things are done:

1. The voltages of each PM and PD tube are monitored continuously.

2. A zero-time signal, triggered from the shot detonator unit, is placed near the start of each digitizer record.

3. A small LED is placed on the detector assembly, and this unit is triggered about $125 \mu \mathrm{s}$ after the shot detonator. In this way, we can verify system integrity for the recording time of interest. Simple shock physics dictates that a nuclear signal would occur between detonator firing and $100 \mu \mathrm{s}$.

These data are recorded by DTRA and their contractor, Allied Signal, in the "horseshoe alcove" of the U1a tunnel complex. The sensitivity and in situ sensitivity of each element of the detector head is shown in Table 12 below. This is shown graphically in Fig. 4.

Table 12. Active Detector Summary.

\section{PM-1 MHD-24/PMH-5}

$\gamma$-Sensitivity @ $\mathrm{Co}^{60}$

n-Sensitivity (@14.1 MeV)

Total signal (gamma + neutron)

PM-2 MHD-24/PMH-5

$\gamma$-Sensitivity @ $\mathrm{Co}^{60}$

n-Sensitivity (@14.1 MeV)

Total signal (gamma + neutron)

PM-3 MHD-24/PMH-5

$\gamma$-Sensitivity @ Co ${ }^{60}$

n-Sensitivity (@14.1 MeV)

Total signal (gamma + neutron)

PD-1 MHD-24/PDH-4

$\gamma$-Sensitivity @ $\mathrm{Co}^{60}$

n-Sensitivity (@14.1 MeV)

Total signal (gamma + neutron)

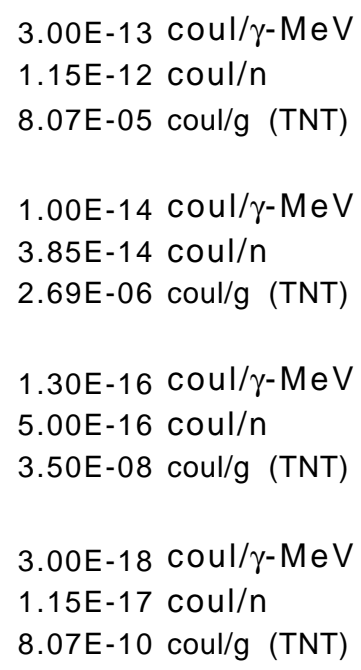




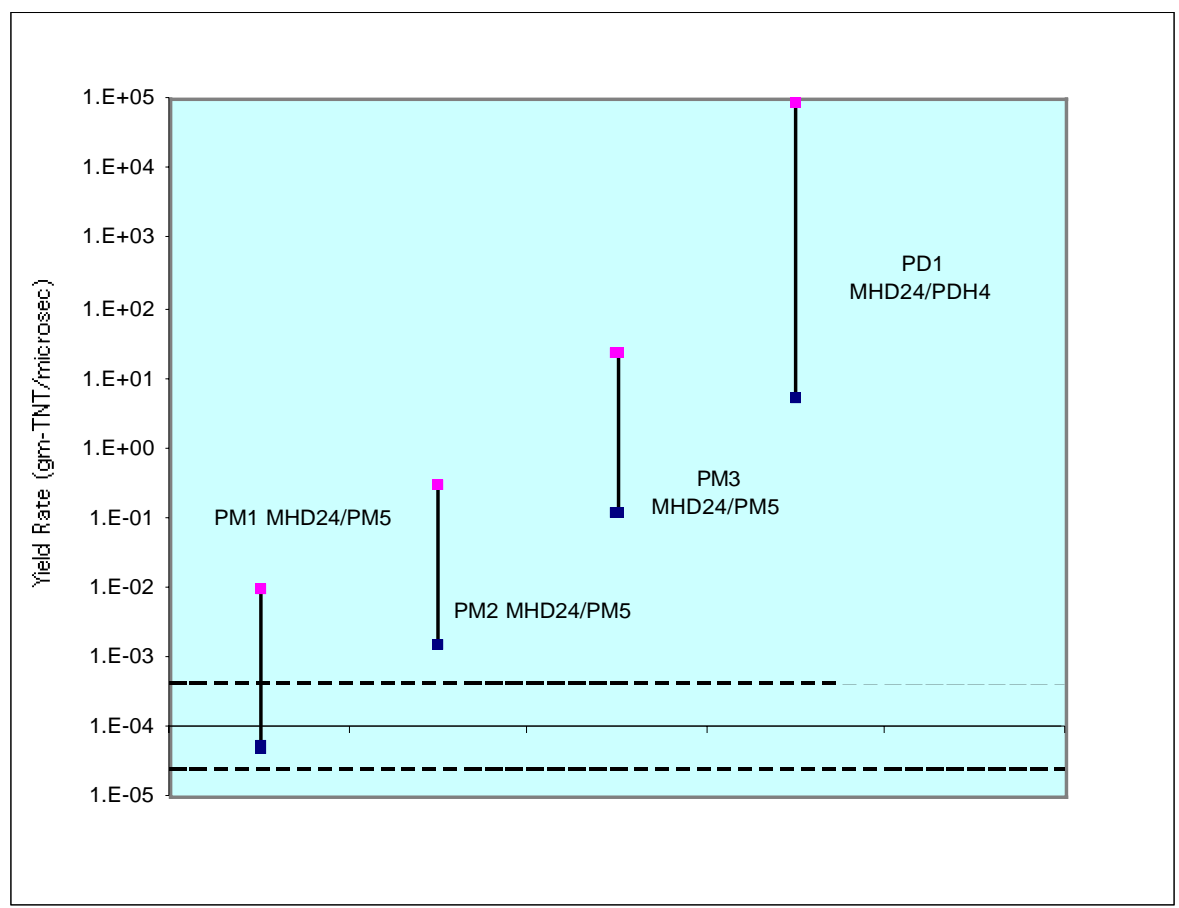

Fig. 4. Transparency Detector Coverage. The dashed lines indicate uncertainties in computing the detector coverage.

We have no good way to calibrate the detectors for sensitivity to neutrons. They are calibrated using gamma rays on the $\mathrm{BN} \mathrm{Co}^{60}$ source, and then the data in the reference ${ }^{\mathrm{iv}}$ is used to derive the neutron sensitivity using the published ratios.

The results from the two active PM tube measurements are shown in Figures 5-13. The first pulse on each record is the "det shaper," which is derived from the fire signal. The second pulse on Oboe 2 and 8 (at about 20 microseconds) is the signal from the radiography x-ray tube. The third pulse (second on Oboe 1 and 3-9) (at about $120 \mu$ s) is a small test light pulsar (LED) on the scintillator crystal to provide a positive indication that the photomultiplier tubes and recording system are working properly. For comparison, the Final Dry Run signal is shown on each plot, offset by -0.3 volts. Fig. 14 shows the electronic "one-line" of the Oboe Transparency system.

The green line is the expected voltage that a 0.1 mg nuclear "explosion," $1 \mu$ s in duration, would produce. Notice that no signals are observed that could possibly be interpreted as a nuclear signal. 
OBOE 1

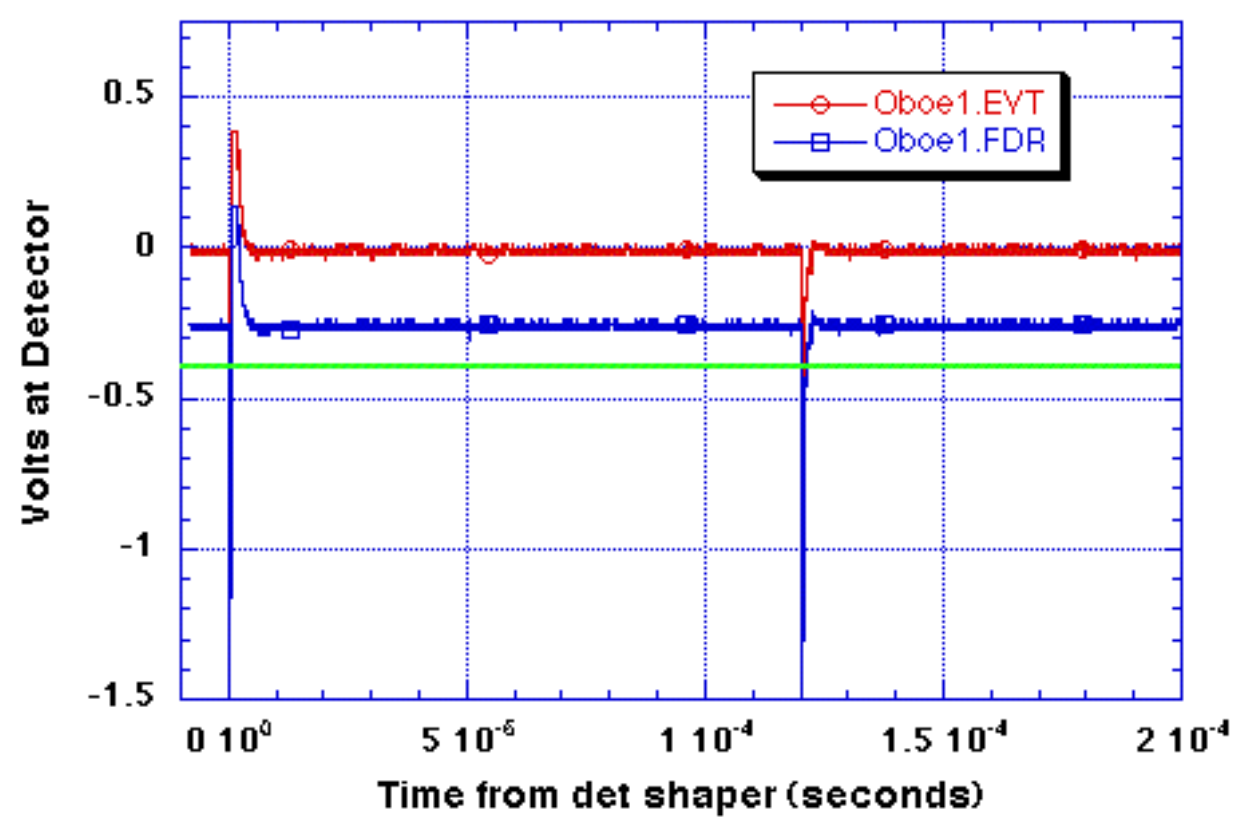

Fig. 5. Oboe 1 Active Detector Results.

OBOE 2

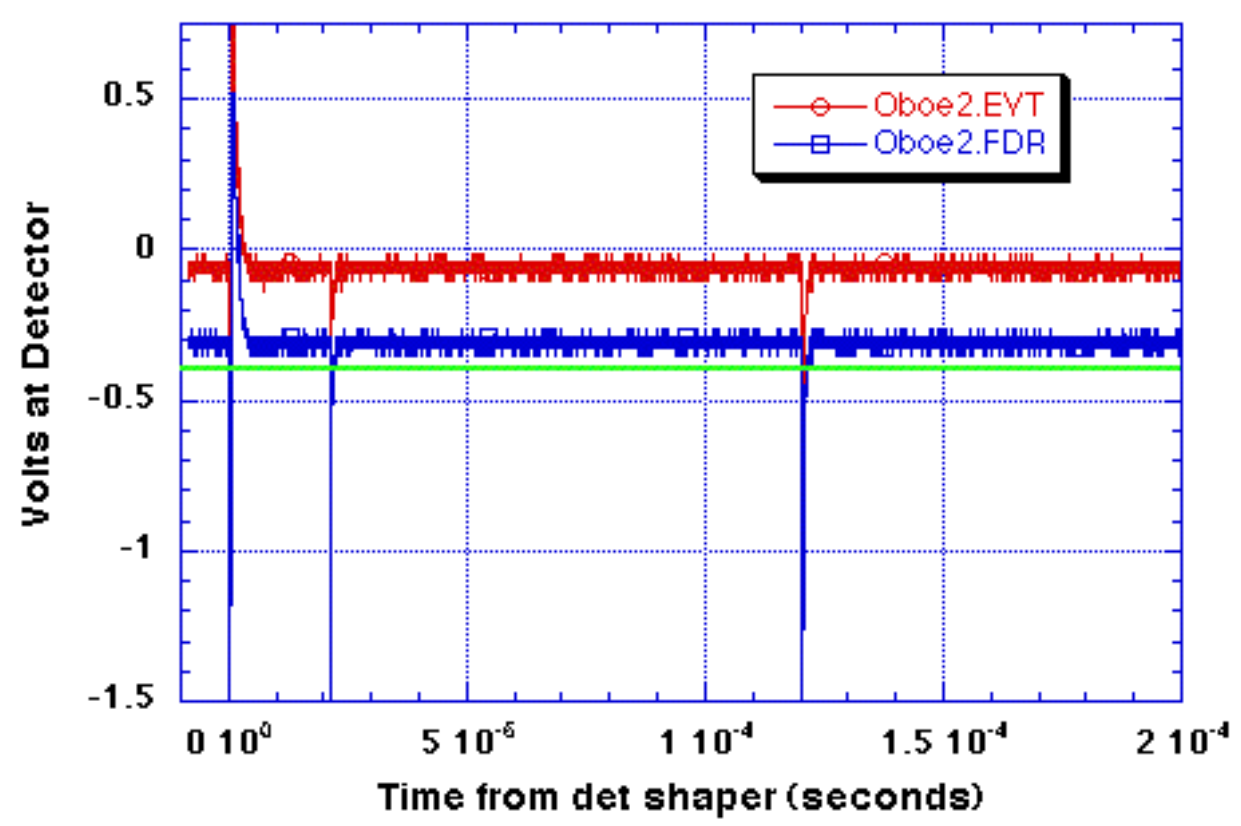

Fig. 6. Oboe 2 Active Detector Results. 
OBOE 3

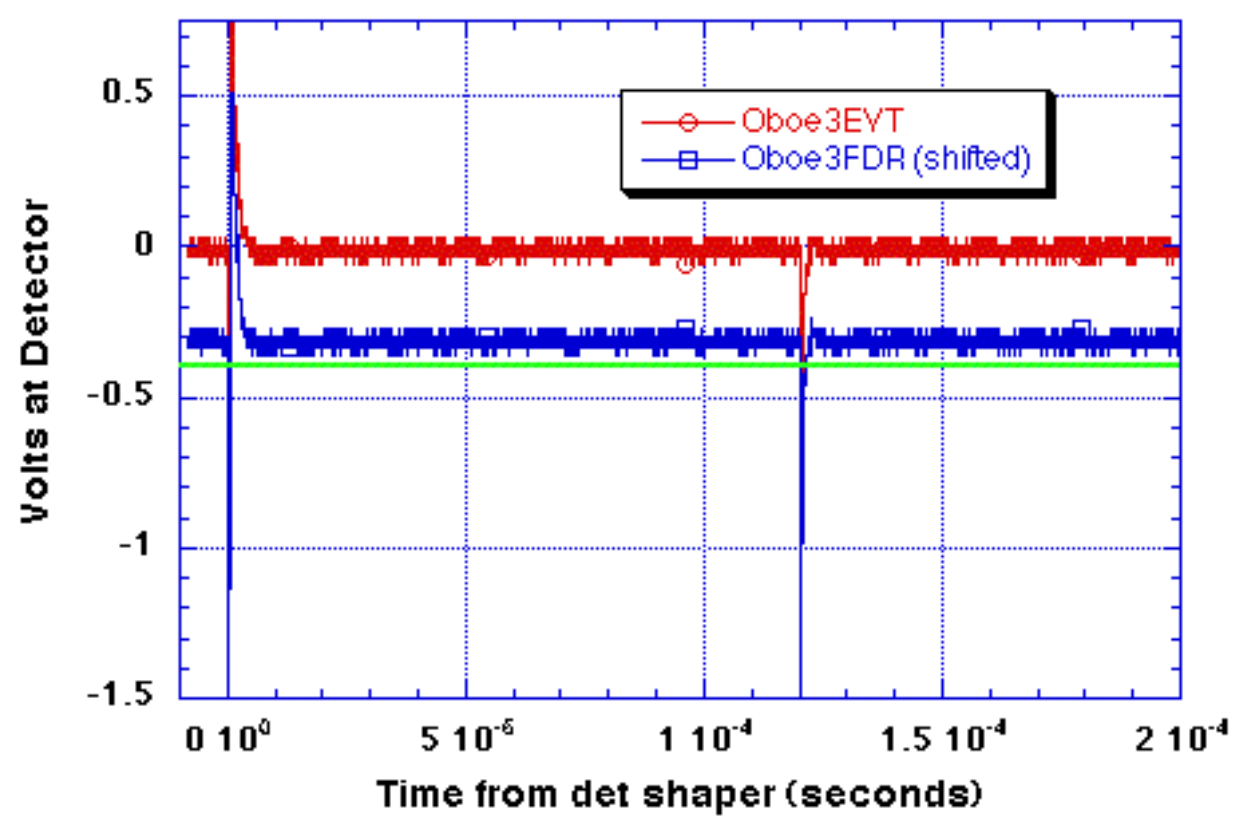

Fig. 7. Oboe 3 Active Detector Results.

OBOE 4

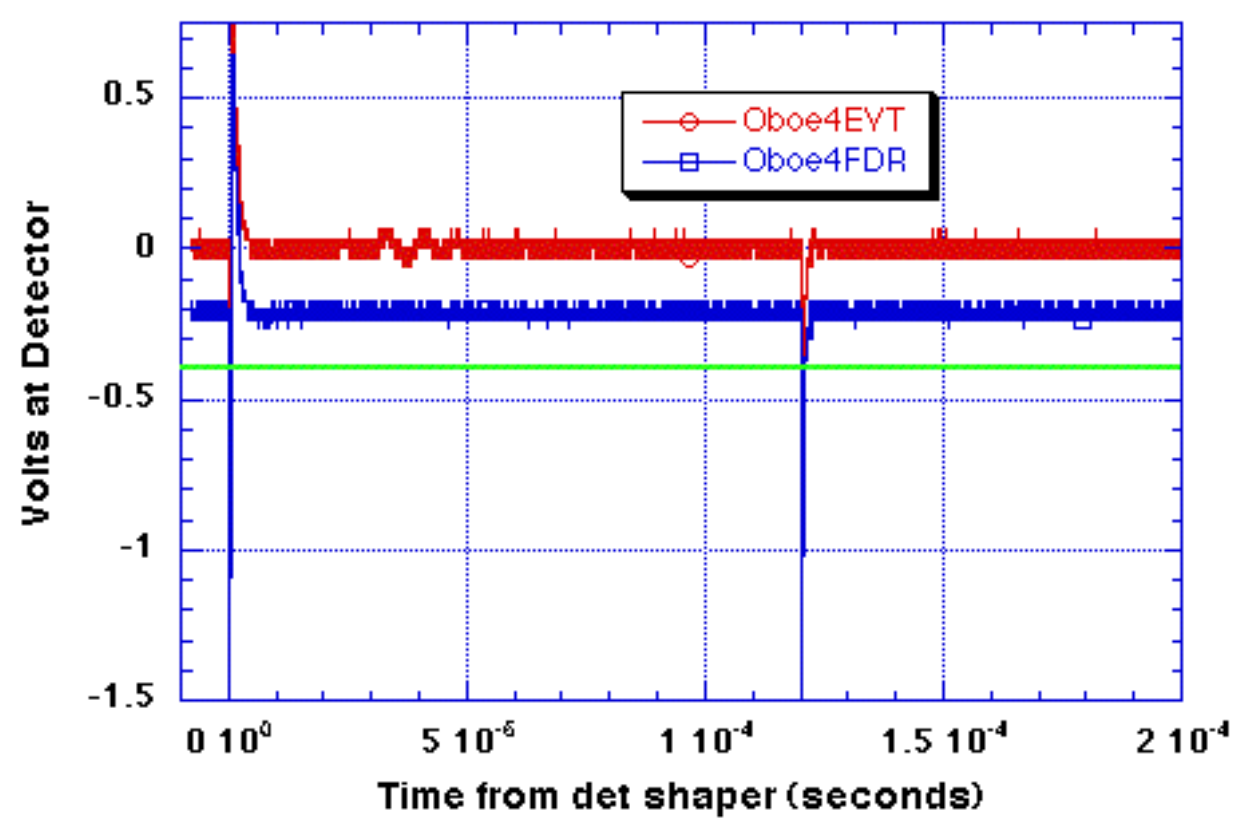

Fig. 8. Oboe 4 Active Detector Results. 


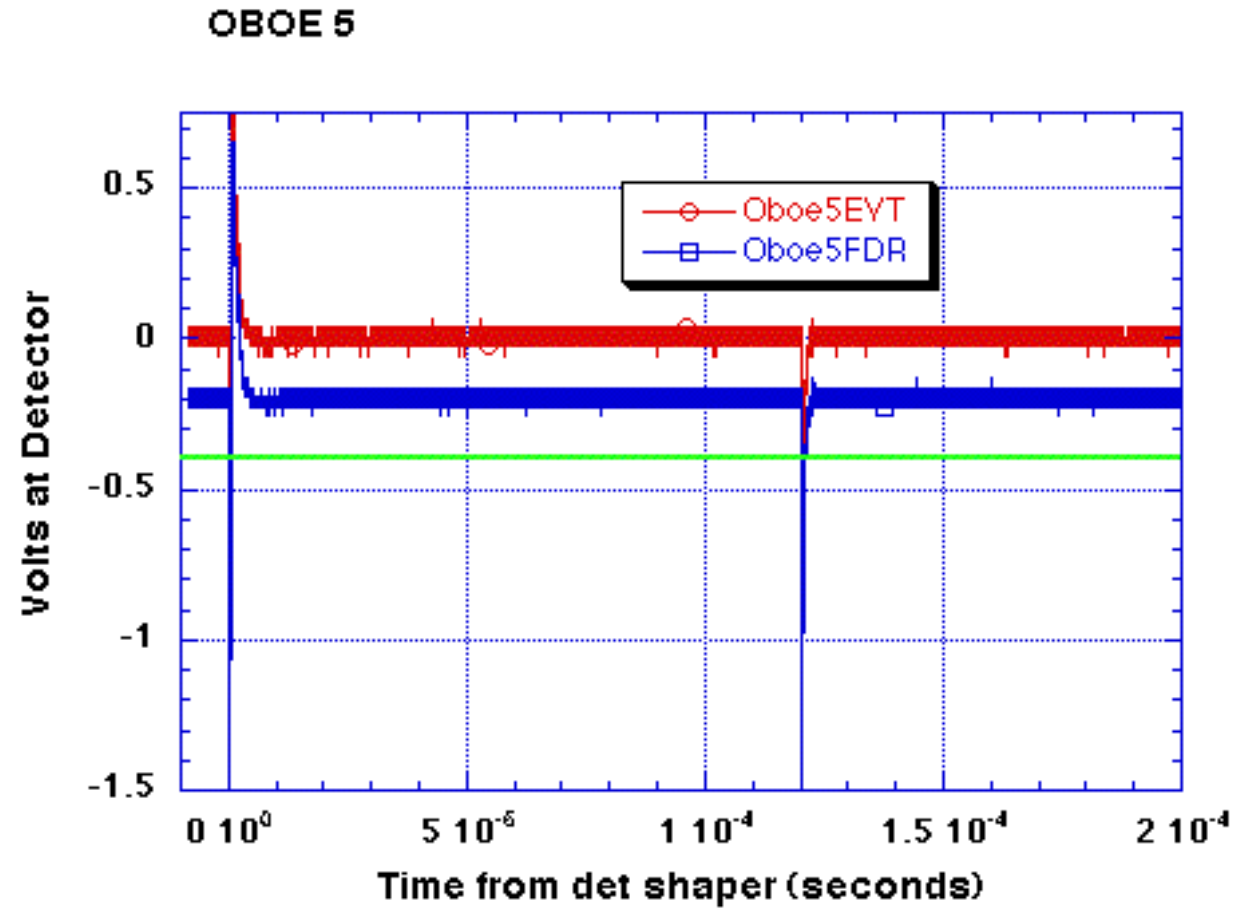

Fig. 9. Oboe 5 Active Detector Results.

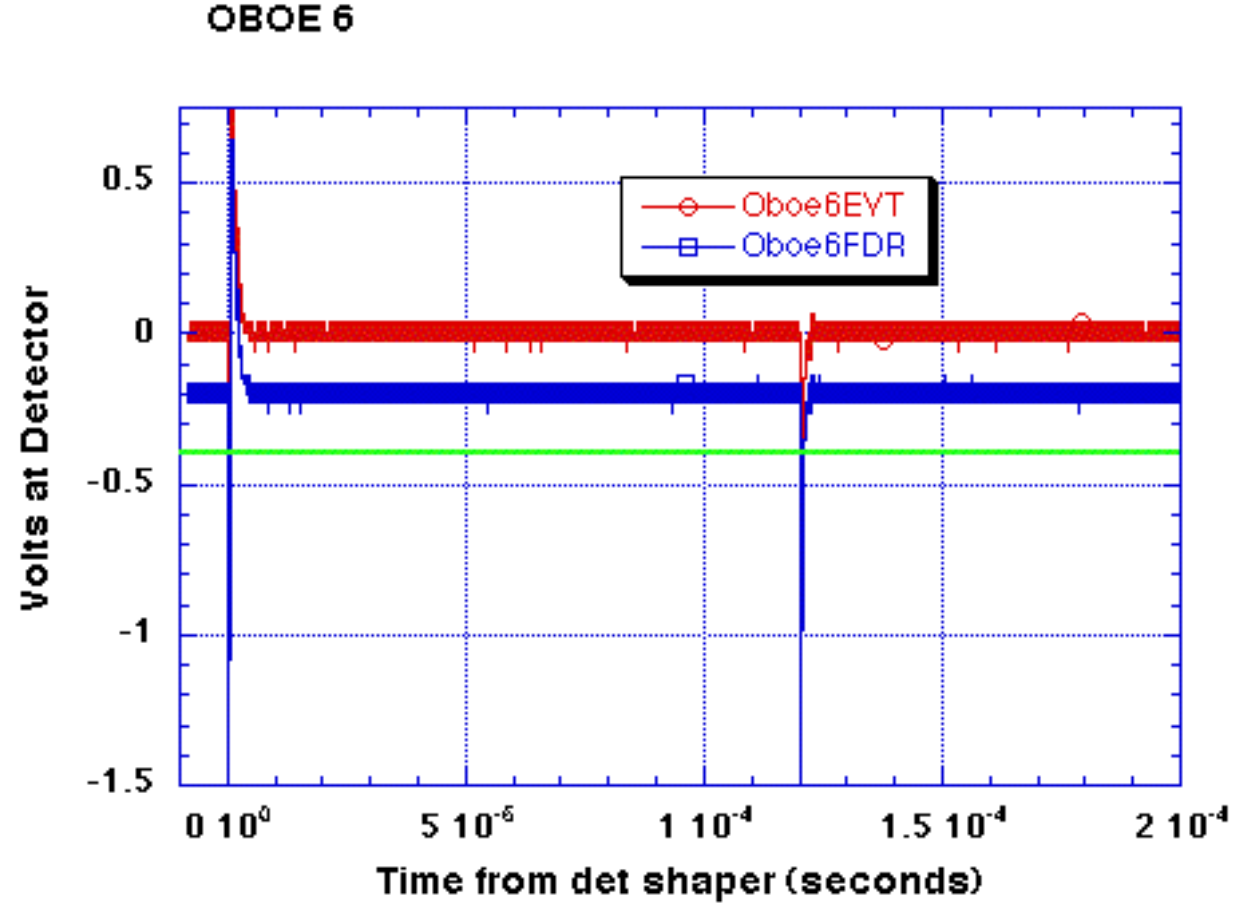

Fig. 10. Oboe 6 Active Detector Results. 
OBOE 7

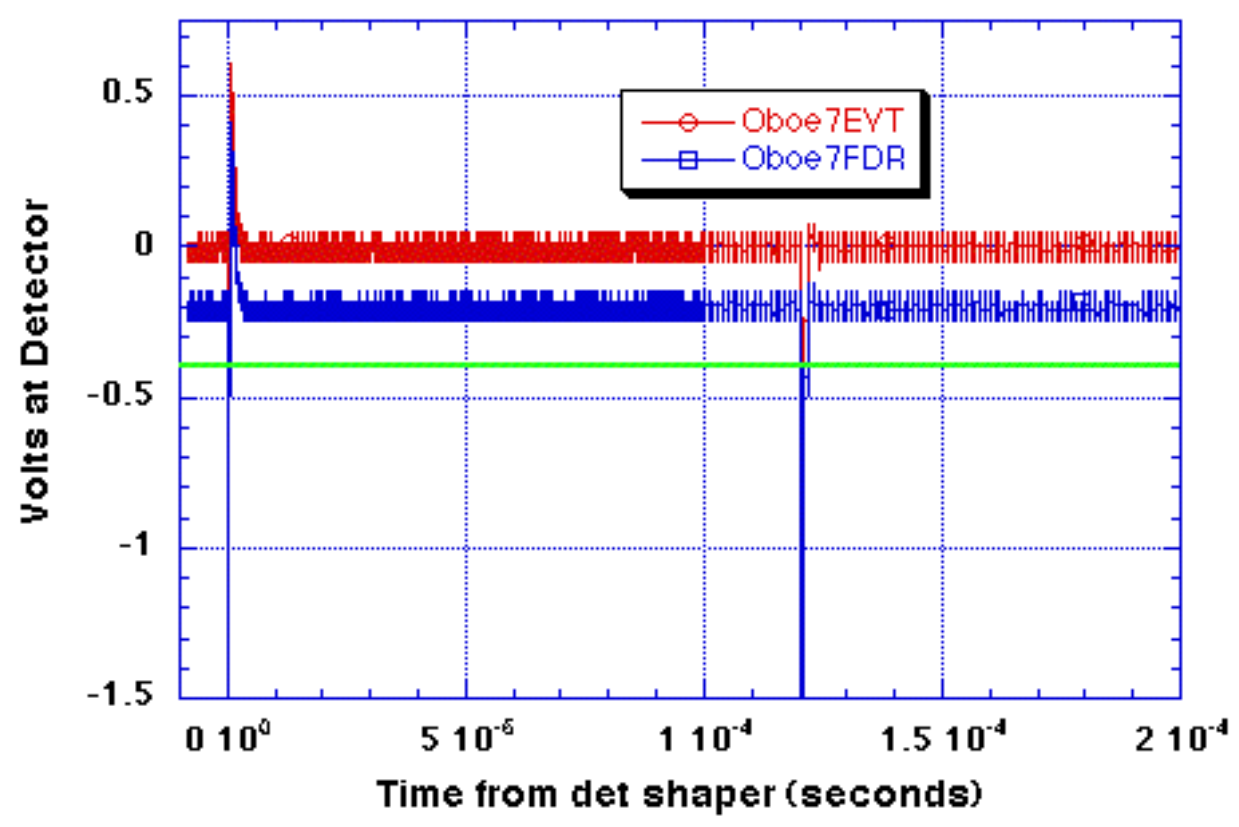

Fig. 11. Oboe 7 Active Detector Results.

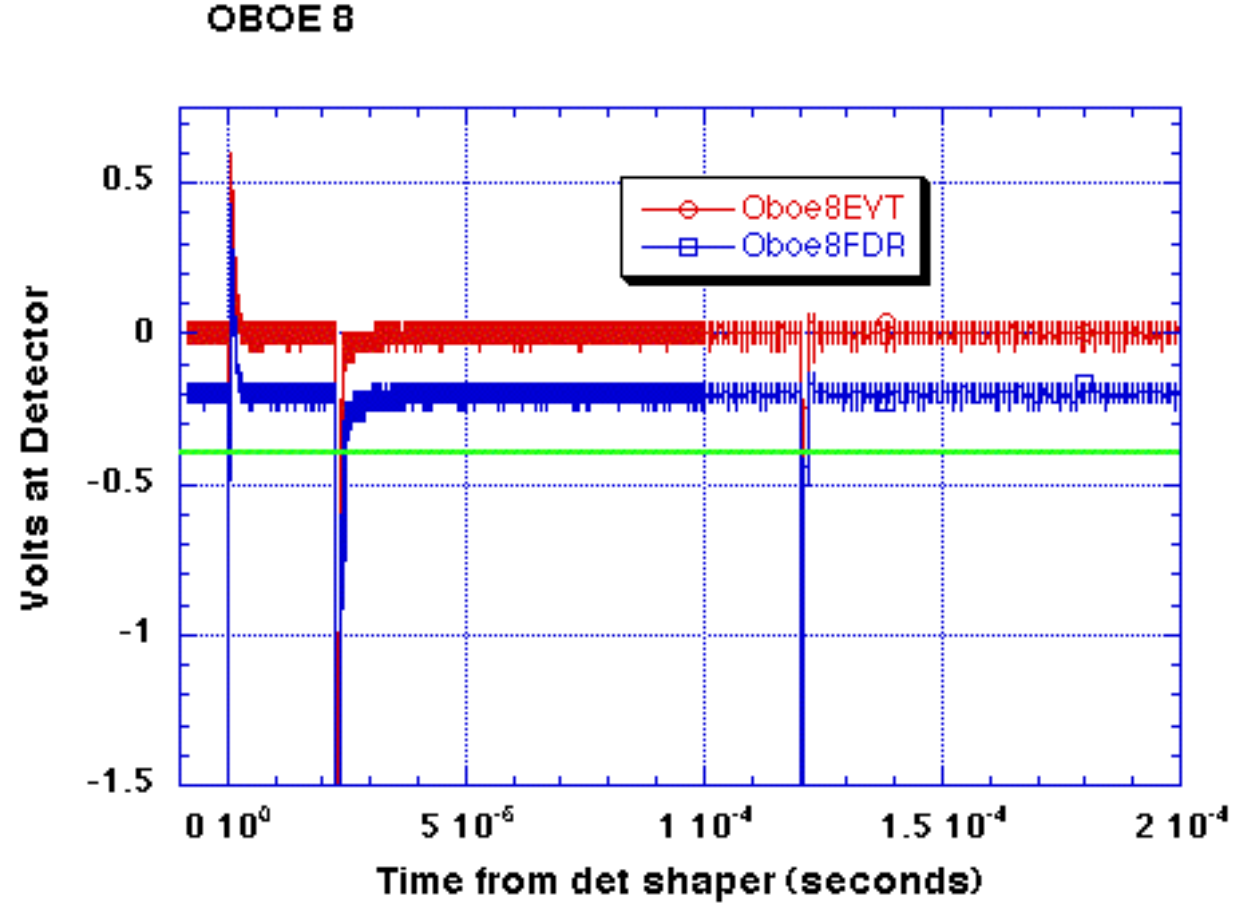

Fig. 12. Oboe 8 Active Detector Results. 


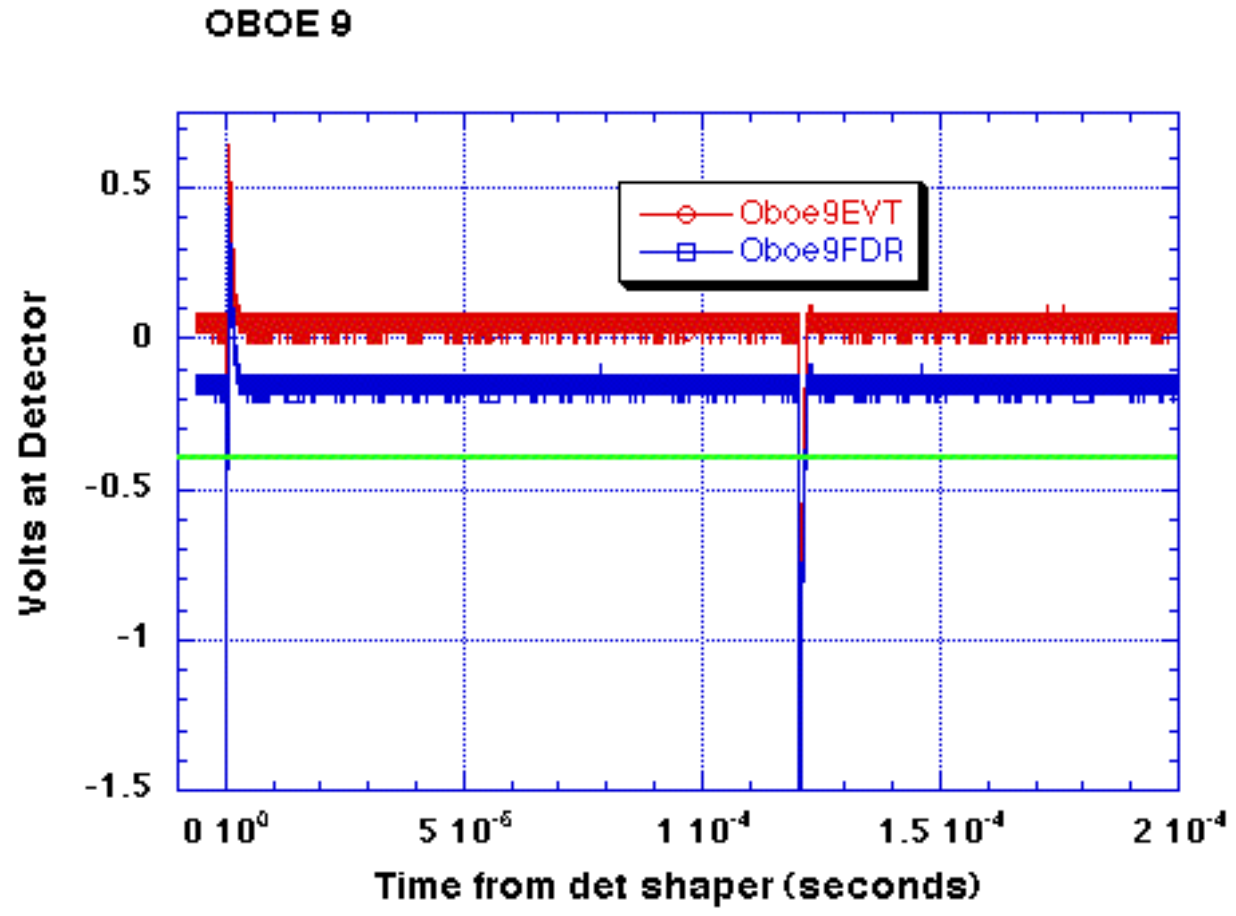

Fig. 13. Oboe 9 Active Detector Results.

\section{Error Budget}

We show below an estimate of the error budget with the major contributors to measurement uncertainties.

Neutron per fission uncertainty $\quad 1.6$

Solid angle uncertainty $\quad 1.6$

Barrier transmission $\quad 1.15$

Detector response 1.2

Total (from adding in quadrature) $\quad 1.9$

\section{Verification Summary}

We have made every effort to make the "Transparency" measurements resistant to spoofing (cheating).

1. The dosimeters are processed "blind," and there are multiple dosimeters.

2. A zero-time fiducial and a light pulse are inserted on each active detector line, thus, establishing that the detector was "alive" during the time at which the SCE was performed. 
3. The voltages on the active detectors are monitored continuously before, during, and after the performance of the SCE, thus, assuring that the transducers were not somehow powered down.

4. The set-up checklist from each SCE is maintained as part of the permanent record of each experiment.

In spite of these precautions, spoofing might still be possible. To perform a more positive verification that we have not been exceeding criticality on LLNL SCEs, a thirdparty verifying organization and much more physical scrutiny of the measurement system would be required.

\section{Conclusion}

For each of Oboe 1-9 we saw no evidence of nuclear energy release above the $0.1 \mathrm{mg}$ threshold, which we established before Oboe. Indeed we saw no sign of any nuclear energy release from any of the dosimeter arrays or the active scintillation detector.

\section{Acknowledgement}

Thanks to Mr. Jack Janne of Bechtel-Nevada for his work in the care and feeding of the active detector package in the Transparency Measurement. Thanks also to the DTRA recording crew: Howard Ross, Mick Coburn, and Jim Tate, et al., for their (almost thankless) job of recording the electronic data on each Oboe. Also, thanks to Ms. Maria Alvarado of Bechtel-Nevada for her work in preparing each neutron dosimeter and her care in processing and analyzing the dosimeter data.

This work was performed under the auspices of the U.S. Department of Energy by the University of California, Lawrence Livermore National Laboratory under contract No. W-7405-Eng-48.

\section{References}

\footnotetext{
${ }^{i}$ T. Wilcox, COG Volume 1. User's Manual, TID Report M-221-1 (Lawrence Livermore National Laboratory, Livermore, CA, 1989).

ii D. L. Clark and E. M. Lent, The Neutron and Gamma Sensitivities of Plastic Scintillators, UOPAD 75-20, (Lawrence Livermore National Laboratory, Livermore, CA, 1975).

iii Lloyd A. Currie, "Limits for Qualitative Detection and Quantitative Determination," Analytical Chemistry, 느, p586 (1968).

${ }^{i v}$ R. G. Geil, Neutron Sensitivity of LLL Detectors, PHY-299 (Lawrence Livermore National Laboratory, Mercury, NV, 1975).
} 


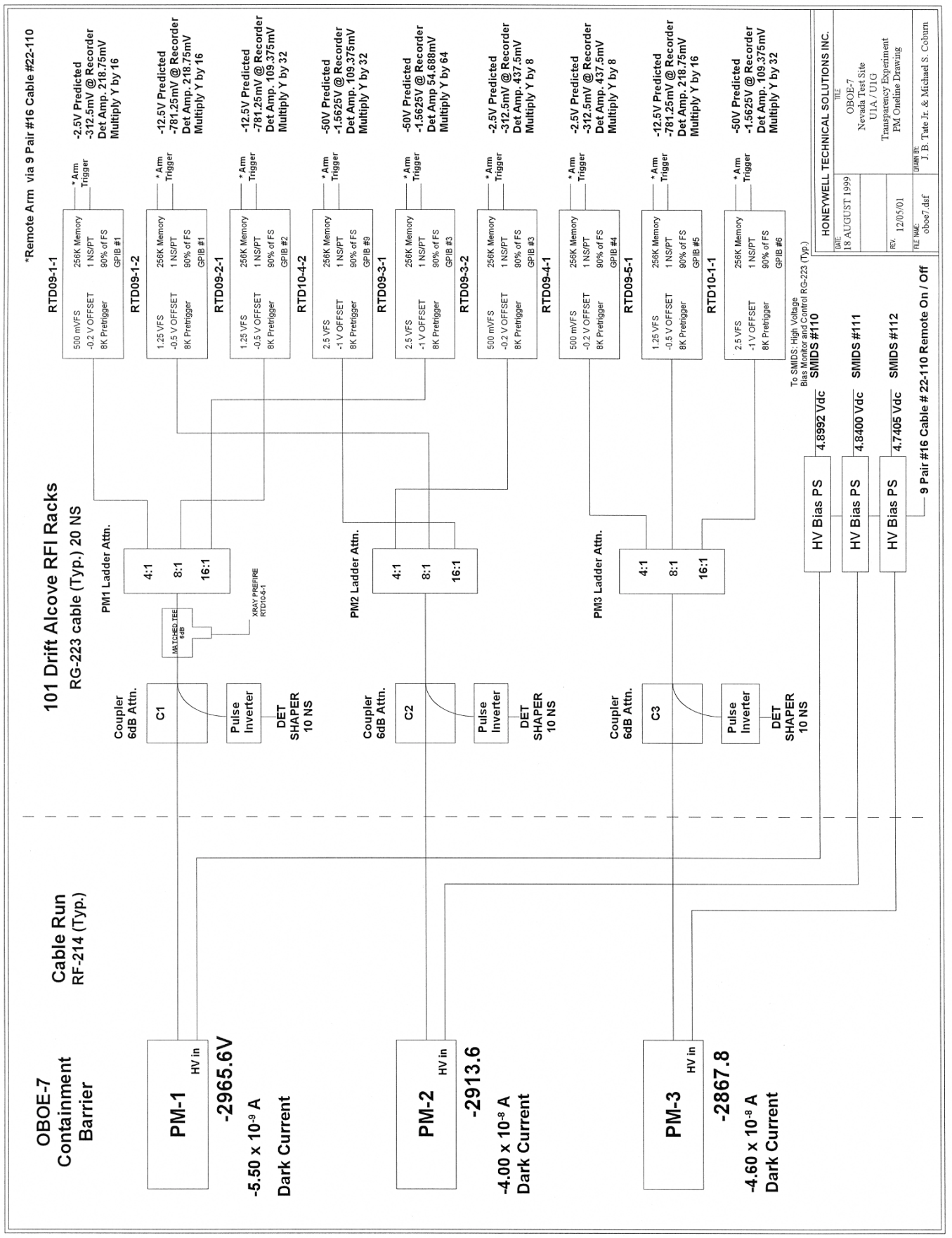

Fig. 14. Oboe Transparency One-Line. 


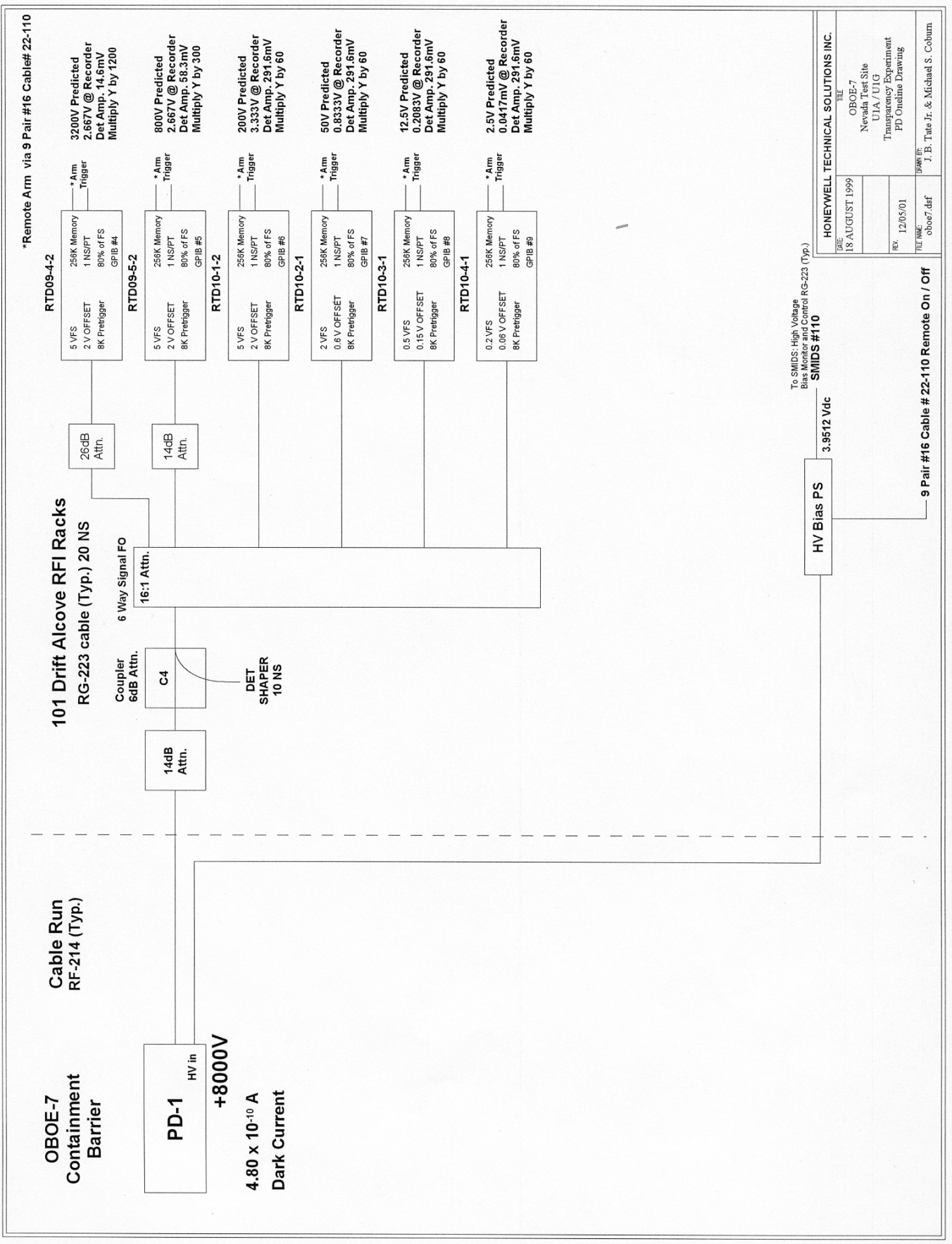

Fig. 14. Continued Oboe Transparency One-line. 


\section{DISTRIBUTION}

\section{LLNL:}

B Division Master Vault $\quad$ L-160

B Division Vault/Reading File L-160

Berzins, Leon L-154

Conrad, David C. L-160

DNT Office Vault, Oboe File L-160

Dunlop, Bill L-175

Egan, Patrick O. L-160

Goodwin, Bruce L-160

Heinle, Raymond A. L-099

Janzen, James L-099

Lear, Dick L-170

McMillan, Charles L-170

Nevada Test Site:

Dekin, Walter L-777

DOE:

Webb, Kerry

Mueller, Lisa

DOE/HQ DP-16

Norman, Jay

$\mathrm{DOE} / \mathrm{NV}$

$\mathrm{DOE} / \mathrm{NV}$

Bechtel Nevada:

Flood, John

Utiger, Edward

Kost, William

Hall, Helen

BN/NTS, Bldg 650, Mercury, NV

$\mathrm{BN} / \mathrm{NLV} 070$

$\mathrm{BN} / \mathrm{NLV} 070$

BN/NLV 070

\section{DTRA}

Ross, Howard

1680 Texas Street, S.E.

Albuquerque, NM 87117-5669 